\title{
Activation Volumes of the Calcium Dependent para-Nitrophenyl Phosphate Hydrolysis of the Sarcoplasmic Reticulum Calcium Transport Enzyme
}

\author{
Klaus Georg König and Wilhelm Hasselbach \\ Max-Planck-Institut für medizinische Forschung, Abteilung Physiologie, Heidelberg, Jahnstr. 29
}

Z. Naturforsch. 39c, 282-288 (1984); received January 16, 1984

Activation Volume, Sarcoplasmic Reticulum, Calcium Dependent para-Nitrophenyl Phosphate, Hydrolysis

The effect of pressure on the calcium dependent hydrolysis of para-nitrophenyl phosphate by the calcium transport enzyme of the sarcoplasmic reticulum was studied under different conditions: temperature, solutes, substrate and ion concentrations. The calcium transport enzyme exhibits a large positive activation volume which does neither depend on the enzyme's inhibition by high salt concentrations nor its activation by ethylene glycol. The activation volume further proves to be pressure-independent but exhibits a pronounced negative temperature coefficient. The volume changes connected with the entrance of para-nitrophenyl phosphate, calcium or magnesium ions into the substrate ion complex are quite small, indicating that the transfer of water connected with the binding of these ligands is compensated by volume changes of the protein, accompanying the transition of the enzyme from its activated into its ground state.

\section{Introduction}

The calcium transport enzyme of the sarcoplasmic reticulum like many other energy transducing enzymes passes through a number of conformational states during its reaction cycle leading to calcium translocation and ATP hydrolysis [1-4]. In quantitative terms, however, these changes in the enzyme's structure accompanying its interaction with magnesium, calcium and ATP are poorly understood. In recent studies conducted with various enzymes, it has been shown that the activation volume can be considered to be a quantitative parameter for the description of structural changes occurring during enzymatic activity [5-7]. The activation volume is derived from the transition state theory which describes the effect of pressure on the reaction rate by the relation [8]:

$$
k_{\mathrm{p}}=k_{0} \cdot e^{\frac{-P \Delta V}{R T}}
$$

where $k_{\mathrm{p}}$ is the reaction rate at a gauge pressure $P$, $k_{0}$ is the reaction rate at one atmosphere, $\Delta V$ is the activation volume and $R$ the gas constant. Hence,

\footnotetext{
Abbreviations: EGTA: ethylene glycol-bis- $(\beta$ aminoethyl $)-$ N,N,N',N'-tetraacetic acid; enzyme: $\mathrm{Ca}^{2+}$ ATPase (EC.3.6.1.3).
}

Reprint requests to Prof. Dr. W. Hasselbach.

0341-0382/84/0300-0282 \$01.30/0 the activation volume is obtained from the dependence of the reaction rate on the hydrostatic pressure.

The inhibition or activation of the reaction by pressure results from its effect on a presumed chemical equilibrium between two reaction intermediates, the transition of which determines the rate of the reaction. This follows because chemical equilibria are affected by pressure if the sum of the volume of the reactants differ from that of the products according to the thermodynamic relation:

$$
K_{\mathrm{p}}=K_{0} \cdot e^{\frac{-P \Delta V}{R T}}
$$

where for example $\Delta V$ is the volume difference between reactant $\mathrm{A}$ and product $\mathrm{B}$ of the reaction $\mathrm{A} \rightarrow \mathrm{B}$ with the equilibrium constants $K_{0}=\mathrm{B} / \mathrm{A}$ at a pressure of one atmosphere and $K_{\mathrm{p}}$ at pressure $P$. As to the physiochemical meaning of the pressure induced volume changes of enzymes or proteins in general, they are essentially assigned to two mechanisms: 1 . The hydration density of the protein is changed due to the exposure of protein residues to water. These residues might either be located on the surface or in the interior of the protein molecule. 2. The volume occupied by the protein itself might be changed. This change has been designated as structural volume change [5].

The effect of pressure on the ATPase activity of the sarcoplasmic reticulum membranes has pre- 
viously been studied by Heremans et al. [9]. The authors related the observed pressure effects to changes in the physical state of the membrane lipids which were assumed to trigger changes in the conformation of the protein. Yet, in these studies no distincton was made between the preparation's total splitting of ATP and its hydrolysis by the calcium dependent transport enzyme. The studies described in the present paper therefore focus on the pressure dependence of the activity of the calcium transport enzyme proper. In order to obtain the activity of the calcium transport enzyme, the calcium independent activity must be measured too and subtracted from the total activity [10]. Furthermore, one has to consider that the calcium dependent hydrolysis by the vesicular shaped membrane fragments of the sarcoplasmic reticulum is strongly inhibited by the calcium concentrated inside the vesicles in the course of the experiment [11]. This effect has to be prevented by making the vesicles permeable for calcium ions with an ionophore [12].

The calcium transport enzyme's natural energy yielding substrate, ATP, is difficult to use in these experiments. The maintenance of a defined substrate concentration and the registration of the reaction process require the use of ATP regenerating and indicating enzyme systems which are themselves pressure sensitive. We therefore performed the experiments with the substrate analog para-nitrophenyl phosphate which allows to monitor the enzymatic activity in a large concentration range by optically measuring the formation of para-nitrophenol. Furthermore, para-nitrophenyl phosphate is not only hydrolytically split by the enzyme but is used as an energy yielding substrate for calcium translocation.

In order to evaluate the volume change occurring in a specified reaction step, we have analyzed the enzyme's activity at different degrees of saturation with respect to each reactant, calcium, magnesium and para-nitrophenyl phosphate. The minimum scheme, necessary to describe the dependence of the enzyme's activity on the concentration of one of the reactants, requires, according to Michaelis and Menten, fast and reversal enzyme substrate complex formation on the one hand and its spontaneous slow and irreversable decay on the other hand. It is the decay of the enzyme substrate complex which limits the rate of the reaction. The transition state theory assignes the rate limiting step to a slow transition from the initially formed enzyme substrate complex (ES) to an hypothetically activated complex ES* as indicated by the following scheme:

$\mathrm{E}+\mathrm{S} \stackrel{K}{\stackrel{K}{\longrightarrow}} \mathrm{ES} \underset{k_{-1}}{\stackrel{k_{1}}{-}} \mathrm{ES}^{*} \stackrel{k_{2}}{\longrightarrow} \mathrm{E}+\mathrm{P} \quad k_{2}$ and $k_{-1} \gg k_{1}$.

For the fully saturated enzyme, this reaction sequence yields the following rate expression:

$$
v=k^{\prime} \cdot e^{\frac{-P \Delta V_{2}}{R T}} \quad k^{\prime}=k_{1} \cdot k_{2} /\left(k_{-1}+k_{2}\right) \sim k_{1} \cdot \alpha
$$

which allows to determine the activation volume for the transition from the nonactivated to the activated complex. On the other hand, the volume change which accompanies the formation of the enzyme substrate complex can be computed from the effect of the pressure on the activity of the unsaturated enzyme. Under these conditions the following relation holds:

$$
v=K \cdot k^{\prime} \cdot c \cdot e^{\frac{-P\left(\Delta V_{1}+\Delta V_{2}\right)}{R T}} .
$$

The volume change is composed of the volume change $\left(\Delta V_{2}\right)$ - the activation volume - and the volume change which occurs when the enzyme combines with one of its reactants $\left(\Delta V_{1}\right)$. Hence, the latter can be obtained by substracting the activation volume $\left(\Delta V_{2}\right)$ from the observed volume change $\left(\Delta V_{2}+\Delta V_{1}\right)$.

For selecting the appropriate concentration of para-nitrophenyl phosphate as well as of the activating ions, calcium and magnesium, the apparent dissociation constant previously reported were used $[14,15]$. To discriminate between volume changes arising from changes in the hydration density of the protein and changes in the volume occupied by the protein itself, we further studied the influence of high salt concentration and of ethylene glycol on the activation volume as it has been proposed by Low and Somero $[5,6]$.

\section{Materials and Methods}

The sarcoplasmic reticulum vesicles were prepared from rabbit skeletal muscle as described by de Meis and Hasselbach [16]. The protein content of the vesicular suspension were determined by the Biuret procedure calibrated by Kjeldahl nitrogen determinations. The para-nitrophenyl phosphatase activity was measured in media containing $6 \mathrm{~mm}$ histidine, $14 \mathrm{~mm}$ sodium glycerophosphate $\mathrm{pH} 7.0$, $20 \mu \mathrm{M}$ of the calcium ionophore Lasolocid and 
$0.2 \mathrm{~mm}$ dithioerythritol. The temperature and the concentration of the reactants, para-nitrophenyl phosphate, magnesium calcium and of modifying agents, $\mathrm{NaCl}$ and ethylene glycol are specified in the legends of figures and tables. The concentration of the vesicles in the assay media were chosen between $0.05 \mathrm{mg} / \mathrm{ml}$ and $0.25 \mathrm{gm} / \mathrm{ml}$ depending on the enzymatic activity under the experimental conditions. The assay media were brought to the respective temperatures prior to the addition of the enzyme. The suspension was subsequently filled into the pressure cell equipped with sapphire windows, Nova Swiss Switzerland, Effretikon. Pressure was generated by a simple hand-driven pump. The pressure was transmitted by silicon oil which was separated from the cell by a two-parted piston sealed with a silicon paste plug in the middle. The pressure was monitored mechanically or electronically. The pressure cell was surrounded by a thermostatically controlled water jacket and installed in a Philips double beam photospectrometer. The reaction was followed by monitoring the appearance of para-nitrophenol at $420 \mathrm{~nm}$ using 8000 for its molar absorbance at $\mathrm{pH}$ 7.0.

In the histidine - glycerophosphate buffered assay media - the absorbance of para-nitrophenol proved to be pressure independent. Activity measurements at $\mathrm{pH} 6.5,7.0,7.5$ revealed that in this $\mathrm{pH}$ range the enzyme's para-nitrophenyl phosphatase activity. is nearly constant. Thus, pressure induced $\mathrm{pH}$ changes as they can occur in the buffer system [17] do not affect substrate hydrolysis.

\section{Results and Discussions}

The results depicted in Fig. 1 demonstrate that the hydrolysis of para-nitrophenyl phosphate proceeds linearly with time for approximately half an hour when the hydrostatic pressure on the reaction medium is stepwise increased. It furthermore shows that rising pressure progressively inhibits enzyme activity and that activity completely recovers when the pressure is released. These experiments were performed in the pressure of calcium $-0.2 \mathrm{~mm}$ in the medium to determine the total splitting and in media containing $2 \mathrm{~mm}$ EGTA to determine basic splitting. The activity pressure relationship for the calcium dependent activity was obtained by substracting for every pressure the measured calcium independent activity from the total activity (Fig. 2).

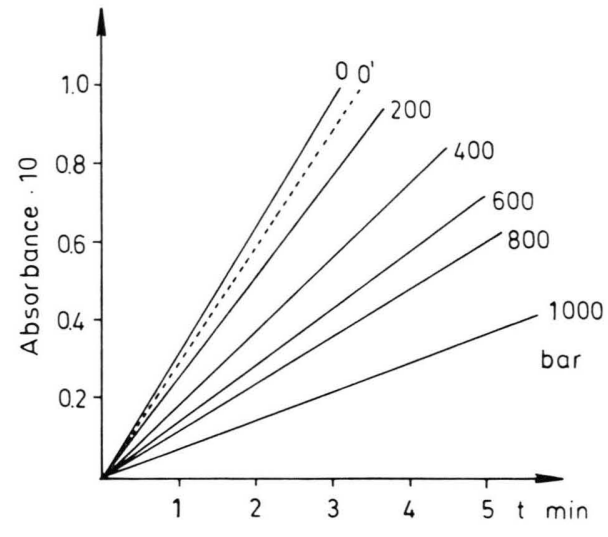

Fig. 1. Inhibition at rising pressure of para-nitrophenyl phosphatase activity of sarcoplasmic reticulum vesicles and its recovery after pressure release. Pressure was stepwise increased and para-nitrophenyl phosphate hydrolysis was continuously registered for $30 \mathrm{~min}$. The progress of the reaction for each pressure step is plotted from the origin: $\mathrm{O}$, before pressure application; $\mathrm{O}^{\prime}$, after pressure release from 1000 bar. The standard medium contained $20 \mathrm{~mm}$ $\mathrm{NaCl}, 10 \mathrm{~mm} \mathrm{MgCl} 2,0.20 \mathrm{~mm} \mathrm{CaCl}, 10 \mathrm{~mm}$ para-nitrophenyl phosphate, $0.1 \mathrm{mg}$ protein $/ \mathrm{ml}$ vesicles, $T=20^{\circ} \mathrm{C}$. On the ordinate the registered absorbance is plotted. Abscissa: Pressure in bar.

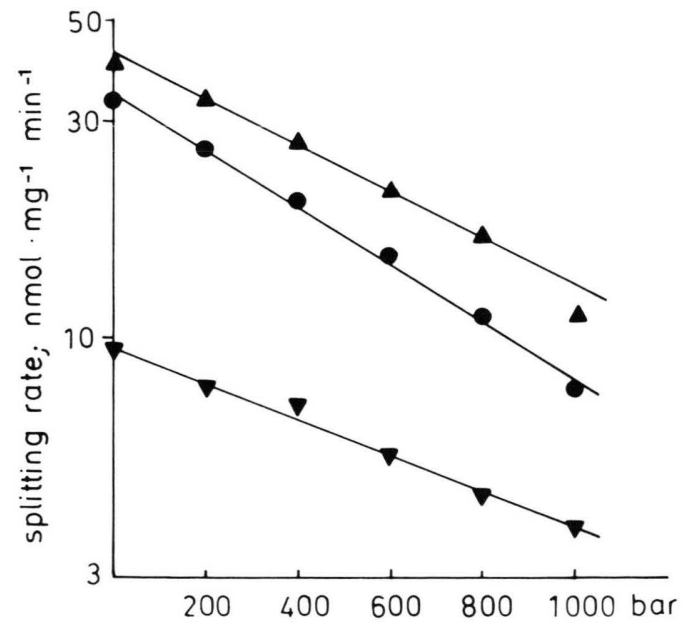

Fig. 2. Effect of pressure on total, calcium independent and calcium dependent para-nitrophenyl phosphate hydrolysis. The standard medium contained $20 \mathrm{~mm} \mathrm{NaCl}, 10 \mathrm{~mm}$ $\mathrm{MgCl}_{2}, 10 \mathrm{~mm}$ para-nitrophenyl phosphate, $0.2 \mathrm{~mm} \mathrm{CaCl} 2$ and $0.05 \mathrm{mg}$ protein $/ \mathrm{ml}, T=30^{\circ} \mathrm{C}$. For measuring calcium independent splitting the medium contained $4 \mathrm{~mm}$ EGTA and $0.25 \mathrm{mg}$ protein $/ \mathrm{ml}$. Total- $\mathbf{\Delta}$, calcium independent- $\mathbf{\nabla}$, calcium dependent- $\bullet$ para-nitrophenyl phosphate hydrolysis. Ordinate: logarithmical plot of the splitting rate. Abscissa: pressure in bar. 

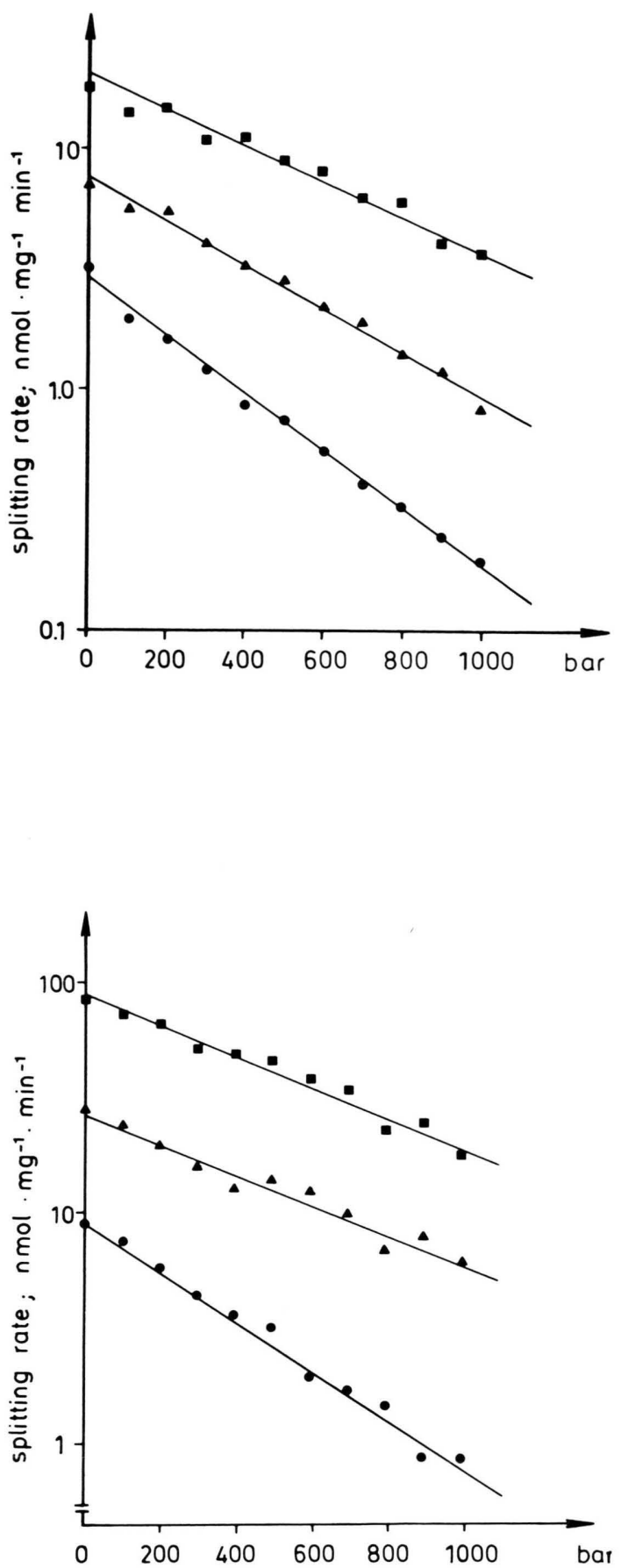

Fig. 3. Pressure induced inhibition of calcium dependent para-nitrophenyl phosphate hydrolysis at different temperatures. The standard assay contained $20 \mathrm{~mm} \mathrm{NaCl}$, $10 \mathrm{~mm} \mathrm{MgCl} 2,0.25 \mathrm{mM} \mathrm{CaCl} 2,0.05-0.25 \mathrm{mg}$ protein $/ \mathrm{ml}$, $1 \mathrm{~mm}$ para-nitrophenyl phosphate in (a) and $10 \mathrm{~mm}$ paranitrophenyl phosphate in (b). $40^{\circ} \mathrm{C}, 30^{\circ} \mathrm{C}, 20^{\circ} \mathrm{C}$. Ordinate: logarithmical plot of the splitting rate. Abscissa: pressure in bar.
The activation volume was computed from the slope of the line resulting from plots of the logarithm of the respective splitting rate as function of the pressure (Fig. 3a, b).

Under all conditions applied in this study, the logarithm activity pressure relation proved to be linear. Hence, the activation volume could be calculated by an exponential curve fitting procedure.

\section{The calcium independent para-nitrophenyl phosphate hydrolysis}

The activation volume of the calcium independent para-nitrophenyl phosphate hydrolysis is significantly larger at low than at high concentration of the substrate $30 \mathrm{ml} / \mathrm{mol}$ versus $20 \mathrm{ml} / \mathrm{mol}$. Between $20^{\circ} \mathrm{C}$ and $40^{\circ} \mathrm{C}$ the activation volume does not significantly depend on the temperature (Fig. 4). In this temperature interval the rate of para-nitrophenyl phosphate hydrolysis increases sixfold corresponding to an activation energy of $18000 \mathrm{cal} / \mathrm{mol}$.

\section{The calcium dependent para-nitrophenyl phosphate hydrolysis}

Like the two experimentally determined activities the total and the calcium independent hydrolysis, their difference, the calcium dependent para-nitrophenyl phosphate splitting, does not exhibit any

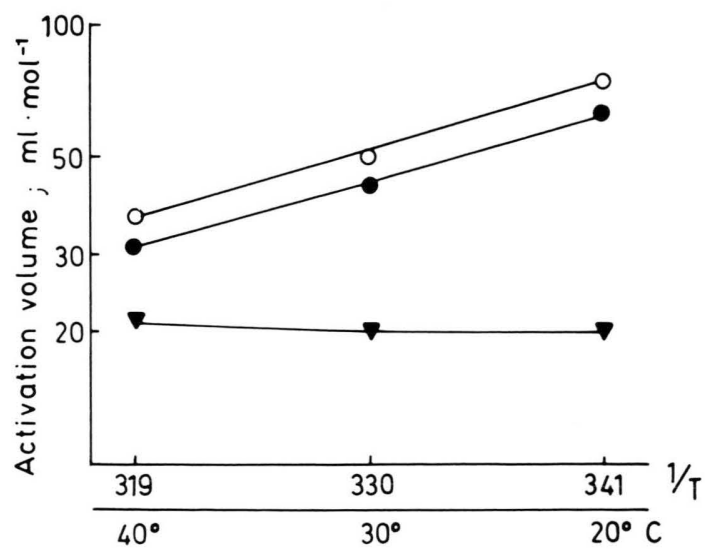

Fig. 4. Activation volume of calcium dependent and calcium independent para-nitrophenyl phosphate hydrolysis at different temperatures. Calcium independent hydrolysis ( $\boldsymbol{\nabla})$ was measured in standard medium containing $20 \mathrm{~mm}$ $\mathrm{NaCl}, 10 \mathrm{~mm} \mathrm{MgCl} 2,10 \mathrm{~mm}$ para-nitrophenyl phosphate, $2 \mathrm{~mm}$ EGTA and $0.2 \mathrm{mg}$ protein $/ \mathrm{ml}$. Calcium dependent hydrolysis was measured in standard media containing $20 \mathrm{~mm} \mathrm{NaCl}, 10 \mathrm{~mm} \mathrm{MgCl}, 0.25 \mathrm{~mm} \mathrm{CaCl}, 10 \mathrm{~mm}$ para-nitrophenyl phosphate $(0)$ or $1.0 \mathrm{~mm}$ para-nitrophenyl phosphate $(\bullet)$. Abscissa: ${ }^{\circ} \mathrm{C}$ and $10^{5} \times 1 / T$. 
break in the logarithm-activity pressure relation, i.e. the activation volume does not depend on pressure. The activation volume of the enzyme fully saturated with para-nitrophenyl phosphate, calcium and magnesium declines from 62 to $32 \mathrm{ml} / \mathrm{mol}$ when the temperature is raised from $20^{\circ} \mathrm{C}$ to $40^{\circ} \mathrm{C}$ (Fig. 4). Thus, the volume change connected with the activation of the enzyme substrate complex has a large negative temperature coefficient. In the same temperature interval the activation energy of

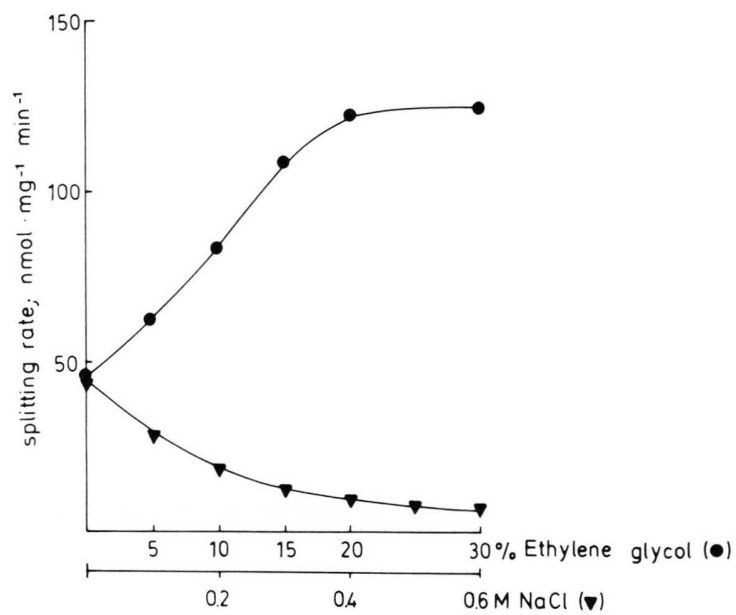

Fig. 5. Modulating effect of $\mathrm{NaCl}(\boldsymbol{\nabla})$ and ethylene glycol (•) or the calcium dependent hydrolysis of paranitrophenyl phosphate by the calcium transport enzyme. The standard assay contained $10 \mathrm{~mm} \mathrm{MgCl}, 0.25 \mathrm{~mm}$ $\mathrm{CaCl}_{2}, \quad 10 \mathrm{~mm}$ para-nitrophenyl phosphate, $0.2 \mathrm{mg}$ protein $/ \mathrm{ml}$ and the concentration of $\mathrm{NaCl}$ and ethylene glycol given on the abscissa, temperature $20^{\circ} \mathrm{C}$.

Table I. Dependence on reaction conditions of volume changes accompanying calcium dependent hydrolysis of para-nitrophenyl phosphate by the sarcoplasmic reticulum calcium transport enzyme. $T=30^{\circ} \mathrm{C}$. The volume changes are means $\pm \mathrm{S}$. E. of $5-8$ experiments.

\begin{tabular}{|c|c|c|c|c|}
\hline \multicolumn{3}{|c|}{ Conditions } & & \multirow{2}{*}{$\begin{array}{l}\text { Volume } \\
\text { change }\end{array}$} \\
\hline $\begin{array}{l}\text { Calcium } \\
{[\mathrm{mm}]}\end{array}$ & $\begin{array}{l}\begin{array}{l}\text { Magne- } \\
\text { sium }\end{array} \\
{[\mathrm{mm}]}\end{array}$ & $\begin{array}{l}\text { para-Nitro- } \\
\text { phenyl- } \\
\text { phosphate } \\
{[\mathrm{mM}]}\end{array}$ & & \\
\hline 0 & 10 & 10 & & $20 \pm 3$ \\
\hline 0 & 10 & 1 & & $30 \pm 3$ \\
\hline 0.25 & 10 & 10 & & $44 \pm 4$ \\
\hline $0.2 \times 10^{-4}$ & 10 & 10 & & $28 \pm 10$ \\
\hline 0.25 & 10 & 1 & & $50 \pm 5$ \\
\hline 0.2 & 1 & 10 & & $33 \pm 5$ \\
\hline 0.2 & 10 & 10 & $0.30 \mathrm{M} \mathrm{NaCl}$ & $36 \pm 4$ \\
\hline 0.2 & 10 & 2 & $0.30 \mathrm{M} \mathrm{NaCl}$ & $45 \pm 4$ \\
\hline 0.2 & 10 & 10 & $20 \% \mathrm{EG}$ & $38 \pm 5$ \\
\hline
\end{tabular}

the enzyme changes from $24000 \mathrm{cal} / \mathrm{mol}$ below to $16000 \mathrm{cal} / \mathrm{mol}$ above $25^{\circ} \mathrm{C}$. In contrast to the marked effect of temperature the ionic strength up to $I=0.3$ does not affect the activation volume, although the enzymatic activity is strongly reduced. Enzme activation as it can be produced by ethylene glycol likewise doe not affect the activation volume (Fig. 5 and Table). As it has been discussed by Low and Somero $[5,6]$, the absence of salt or solvent effects on the activation volume indicates that hydration or dehydration of amino acid side-chains and/or peptide linkages do not contribute to the observed activation volume. Hence, the observed activation volume most likely arises from a structural volume change.

The pressure invariance of the activation volume is in contrast to the result of Heremans et al. [9] who studied the pressure effect on the splitting of ATP by the calcium transport enzyme. The break in the logarithm-activity pressure relation observed by the authors were interpreted as being the result of a change in the conformation of the protein or its state of association mediated by pressure induced phase transition of the membrane lipids. Yet, if the enzymatic activity should be affected by the pressure via its action on the lipids, the pressure should equally influence the interaction of all substrates with the enzyme. This is evidently not the case. The lipid hypothesis is further difficult to reconcile with our observation that modulation of the lipid matrix by Triton X-100 or phospholipase $\mathrm{A}_{2}$ digestion does only very little affect the activation volume (unpublished results). A similar discrepancy concerning the logarithm-activity pressure relation exists for the hydrolysis of ATP and para-nitrophenyl phosphate by the $(\mathrm{Na}, \mathrm{K})$-ATPase. The enzyme's small activation volume for para-nitrophenyl phosphate hydrolysis and its independence on pressure contrasts to the much larger activation volume of ATP hydrolysis and the distinct break in its logarithm-activity pressure relation. De Smedt et al. [18] attributed this splitting mode of para-nitrophenyl phosphate to its splitting by only the terminal potassium dependent segment of the reaction cycle of the $(\mathrm{Na}, \mathrm{K})$-ATPase. This explanation fails in the case of the calcium transport enzyme because the para-nitrophenyl phosphate is a complete substrate analog able to drive calcium transport effectively.

The volume expansion deduced for the transition of the initial enzyme substrate complex to the 
activated complex must be reversed in the reaction sequence leading from

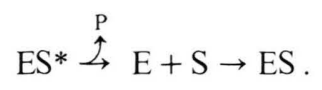

The volume changes in this sequence connected with binding of the three ligands can be obtained from the volume change exhibited by the calcium transport enzyme partially saturated with the respective ligands. Under the presumption that the volume change of the subsaturated enzyme comprises in addition to the volume change of the activating step - activation volume - the volume change resulting from the binding of the respective reactant with the enzyme, the activation volume for the formation of the initial enzyme substrate complex is simply obtained by substraction of the respective numbers given in the Table. Yet, the volume change computed for a given set of reactant concentrations cannot unambiguously be related to the binding of a distinct reactant. Such an assignment requires knowledge concerning the order in which the reactants are bound: Sequential binding modes or random binding with independent or dependent binding steps. Yet, these complications can largely be ignored due to the fact that the computed volume changes are quite small, being positive when the concentrations of magnesium or para-nitrophenyl phosphate are suboptimal or slightly negative for the enzyme subsaturated with calcium.

Thus, the volume changes computed for the completion of the reactant cycle are smaller than the expected change of $44 \mathrm{ml} / \mathrm{mol}$. This apparent deviation can tentatively be explained if we consider that magnesium and calcium ions loose at least part of their hydration shell when the initial enzyme substrate complex is formed. In the hydration shell of both ions the density of water is much higher than in the surrounding medium as deduced from the fact that calcium and magnesium have negative partial molar volumes of $20-30 \mathrm{ml}$, respectively [19]. When the ions are bound by the protein, the ions' hydration shells become smaller or are lost (c.f. [20]). The release of bound water should result in a volume increase. Since no change or only a small volume decrease has been observed in our experiment, the predicted volume increase, due to the release of water from the ions, has evidently compensated for the volume decrease of the protein.
The large water movement of $18 \mathrm{~mol}$ per reaction cycle proposed by Dupont [4, 21] as being an essential feature of calcium transport mechanism is not detectable as a pressure sensitive volume change. The transfer for these quantities of solvation water can occur volume neutral only either if the volume change connected with the primary hydration is compensated by secondary volume changes or if it takes place in a reaction step which is neither pressure sensitive nor rate limiting.

\section{Conclusions}

The calcium transport enzyme exhibits a quite large positive activation volume for the hydrolysis of the calcium transport supporting pseudo-substrate para-nitrophenyl phosphate. As in the case of ATP hydrolysis by the (Na,K)-ATPase, structural changes in the enzyme substrate complex occurring during calcium dependent hydrolysis, evidently, compensate the negative volume changes as they are characteristic for the hydrolytic decomposition of "energy rich" phosphate compounds (c.f. [18]). Since pressure like temperature is known to affect the physical state of the membrane lipids, the observed pressure independence of the activation volume indicates that pressure induced changes do not discernably affect the enzyme's activity. A most remarkable property of the activation volume is its pronounced temperature coefficient. A similar negative correlation between activation volume and temperature has previously been reported for the oligomeric enzyme glutamate dehydrogenase and explained by the assumption that the increase of the intermolecular free volume produced by rising temperature, is accompanied by solvent binding to the newly exposed protein residues resulting in a decrease of the volume change [7]. This explanation illustrates the difficulties to assign structural changes of the molecule to observed volume change. The fact that activation volume is neither affected by high salt concentrations nor by change in the nonionic solute, ethylene glycol indicates that solvent changes do not essentially contribute to the observed activation volume. For various enzymes Low and Somero [5, 6] et al. have shown that the activation volume is strongly affected by salts and they suggested that water density modifying groups on the protein surface were changing the exposure 
to water during catalysis. The salt insensitive activation volume of the calcium transport enzyme thus argues for the preponderance of the structural contributions arising from changes in the volume of the protein itself.

According to the bipartition of the reaction chain, substrate binding and activation of the enzyme substrate complex, the reaction step connected with this structural change must be assigned to the activation of the enzyme substrate complex. In the multi-step reaction cycle, proposed for the calcium enzyme (c.f. $[1-4]$ ), the activation step might correspond to one or more reaction steps which limit the reaction rate and which are most pressure sensitive. On the other hand, the formation of the enzyme ion substrate complex can be assigned more precisely to the reaction sequence following the release of inorganic

[1] W. Hasselbach, Top. in Current Chem. 78, 1-56 (1979).

[2] G. Inesi, in Cell and Muscle Motility, (R. M. Dowben and E. W. Shay, eds.), Vol. I, pp. 63-97, Plenum Press, New York 1981.

[3] L. de Meis, The Sarcoplasmic Reticulum, Transport in the Life Science (E. E. Bittar, ed.), Wiley \& Sons, New York 1981.

[4] Y. Dupont, FEBS Lett. 161, 14-20 (1983).

[5] P. S. Low and G. N. Somero, Proc. Nat. Acad. Sci. USA 72, 3014-3018 (1975).

[6] P. S. Low and G. N. Somero, Proc. Nat. Acad. Sci. USA 72, 3305-3309 (1975).

[7] Karel Heremans, Ann. Rev. Biophys. Bioeng. II, $1-21$ (1982).

[8] S. Glasstone, K. J. Laidler, and H. Eyring, The Theory of Rate Processes, The McGraw Hill Book Co., Inc. New York-London 1941.

[9] K. Heremans and F. Wuytack, FEBS Lett. 117, $161-163$ (1980).

[10] W. Hasselbach and M. Makinose, Biochem. Z. 339, 94-111 (1963). phosphate and the entrance of the reactants into the reaction chain. The small volume change found for this reaction points to the compensating effect of a number of volume changes. The chelation of magnesium and calcium ions by the enzyme should result in a volume increase due to the release of water from their hydration shell, while, on the other hand, the return of the activated enzyme in its ground state should cause a volume decrease. Evidently, these opposing effects largely cancel each other.

\section{Acknowledgements}

The excellent technical assistance of Mrs. Lore Stephan is appreciated. This work was in part supported by the Deutsche Forschungsgemeinschaft.

[11] W. Hasselbach, Ann. N. Y. Acad. Sci. 137, 1041-1048 (1966).

[12] A. Scarpa, I. Baldassare, and G. Inesi, J. Gen. Physiol. 60,735-749 (1972).

[13] G. Inesi, Science 171, $901-903$ (1971).

[14] R. The and W. Hasselbach, Eur. J. Biochem. 74, 611-621 (1977)

[15] W. Hasselbach, E. Fassold, A. Migala, and B. Rauch, Fed. Proc. 40, 2657-2661 (1981).

[16] L. de Meis and W. Hasselbach, J. Biol. Chem. 246, 4759-4763 (1971).

[17] A. Distèche, Symp. Soc. Exp. Biol. 26, 27-60 (1972).

[18] H. de Smedt, H. Borghgraef, R. Ceuterick, and F. Heremans, Biochem. Biophys. Acta 556, 479-489 (1979).

[19] A. Eucken, Lehrbuch der chemischen Physik II, 2, Akademische Verlagsgesellschaft Leipzig 1944.

[20] R. Winkler and M. Eigen, in Mol. Bioenergetics and Macromol. Biochemistry (H. H. Weber, ed.), Springer Verlag Berlin, Heidelberg, New York 1972.

[21] Y. Dupont and R. Pougeois, FEBS Lett. 156, 93-98 (1983). 